Original Article

\title{
The correlation between muscle activity of the quadriceps and balance and gait in stroke patients
}

\author{
Dae Jung Yang, PhD, PT ${ }^{1)}$, Seung Kyu Park, PhD, PT ${ }^{1)}$, Yo Han Uhm, PT $^{1)}$, \\ Sam Heon Park, $\mathrm{PT}^{1)}$, Dong Whan Chun, $\mathrm{PT}^{1)}$, Je Ho Kim, PhD, $\mathrm{PT}^{1)^{*}}$ \\ 1) Department of Physical Therapy, Graduate School of Physical Therapy, Sehan University: \\ 1113 Noksaek-ro, Samho-eup, Yeongam-gun, Jeollanam-do, Republic of Korea
}

\begin{abstract}
Purpose] The purpose of this study was to examine the correlation between quadriceps muscle activity and balance and gait in stroke patients. [Subjects and Methods] Fifty-five stroke patients (30 males 25 females; mean age 58.7 years; stroke duration 4.82 months; Korean mini-mental state examination score 26.4) participated in this study. MP100 surface electromyography, BioRescue, and LUKOtronic were used to measure the quadriceps muscle activity, balance, and gait, respectively. [Results] There was a significant correlation between quadriceps muscle activity (vastus lateralis \% reference voluntary contraction, vastus medialis $\%$ reference voluntary contraction) and balance (limits of stability) and gait (gait velocity) but there was none between vastus lateralis \% reference voluntary contraction, vastus medialis \% reference voluntary contraction. [Conclusion] An increase in quadriceps muscle activity will improve balance and gait ability. To improve function in stroke patients, training is needed to strengthen the quadriceps muscles.

Key words: Muscle activity, Balance, Gait
\end{abstract}

(This article was submitted Feb. 4, 2016, and was accepted May 14, 2016)

\section{INTRODUCTION}

Stroke damages the sensory-motor system, leading to limitations in daily activity, increased risk of falling, and decreased functional independence ${ }^{1,2)}$. Stroke causes muscle weakening in patients due to a decrease in the rate of motor unit recruitment and weakness of selective type II fibers ${ }^{2}$, with decreased extension torque in knee joints on the nonparalyzed and paralyzed side when compared to that of healthy individuals of the same age ${ }^{3)}$. Among the lower extremity muscles, the quadriceps provides stability during stance phase in the gait cycle and supports normal posture alignment on the knee joint. Coordination between the vastus lateralis and vastus medialis is necessary for the normal function of the knee joint. Quadriceps muscle strength is a very important factor in the functional recovery of stroke patients ${ }^{4}$. Balance refers to the ability to maintain upright posture when dynamic gravitational change occurs. Stroke patients show difficulty in functional performance such as gait due to decreased limits of stability (LOS) and an increase in postural sway while maintaining upright postures ${ }^{5}$.

Gait is controlled through interactions of many systems, such as the nervous and musculoskeletal systems, and a continuous, repeating posture that moves the body forward ${ }^{6}$. Stroke patients face limitations in daily activities due to slow, unstable gait. Thus, the main objective in rehabilitation of stroke patients is a fast, effective gait. This is an important index in judging the prognosis ${ }^{7}$.

This study aims to provide basic data for the rehabilitation of stroke patients by analyzing correlations between quadriceps muscle activity and balance and gait velocity in stroke patients.

*Corresponding author. Je Ho Kim (E-mail: albam20@naver.com)

(C2016 The Society of Physical Therapy Science. Published by IPEC Inc.

This is an open-access article distributed under the terms of the Creative Commons Attribution Non-Commercial No Derivatives (by-nc-nd) License $<$ http://creativecommons.org/licenses/by-nc-nd/4.0/>. 


\section{SUBJECTS AND METHODS}

This study was approved by the bioethics Committee of Sehan University Center (institutional review board approval number: 2015-04) on July 28, 2015. This study selected 55 patients who received inpatient treatment after the diagnosis of stroke. Patients read and signed an informed consent form before the start of the study. The selection criteria were hemiplegia on the right side, ability to communicate, a score higher than 24 points in the Korean Mini-mental State Examination, ability to walk more than $10 \mathrm{~m}$ independently, and without muscular or skeletal system diseases that could affect the experiment. MP100 (Biopac system Inc., USA) surface EMG was used to measure the quadriceps muscle activity; muscle activity was measured for the vastus lateralis and vastus medialis. The sampling rate was $1,024 \mathrm{~Hz}$, a notch filter was used at $60 \mathrm{~Hz}$, a band pass filter was used at 30-450 Hz, and collected signals were managed with root mean squares. To normalize the muscle activity, \% reference voluntary contraction (\%RVC) was used ${ }^{8)}$. BioRescue (RM Ingenierie, France) was used to measure balance ability. Moving distance and moving area of the center of pressure were measured, as well as LOS ${ }^{9}$. LUKOtronic (Lutz-Kovacs Electronic, Austria) motion analysis system was used to analyze gait velocity as the temporal and spatial variance of gait, and collected data were analyzed using GaitLab (Lutz-Kovacs Electronic, Austria) ${ }^{10)}$.

SPSS (IBM Co., Armonk, NY, USA) ver. 18.0 statistical software was used to analyze the results. Characteristics of subjects used descriptive statistics. Correlations between quadriceps muscle activity and balance and gait velocity were assessed using Pearson's correlation coefficient. Statistical significance level was set as $\alpha=0.05$.

\section{RESULT}

Table 1 summarizes the data for gait velocity, limits of stability, and muscle activity of the vastus lateralis (VL) and vastus medialis (VM), along with the general characteristics of the subjects. Table 2 summarizes the correlation between quadriceps muscle activity and balance and gait velocity. A significant correlation was found between VL \%RVC and LOS $(\mathrm{r}=0.75$, $\mathrm{p}<0.01)$ and gait velocity $(\mathrm{r}=0.74, \mathrm{p}<0.01)$; however, no significant correlation was observed for VM \%RVC. There was a significant correlation between VM \%RVC and LOS $(r=0.85, \mathrm{p}<0.01)$ and gait velocity $(\mathrm{r}=0.86, \mathrm{p}<0.01)$, and also between LOS and gait velocity $(\mathrm{r}=0.85, \mathrm{p}<0.01)$.

\section{DISCUSSION}

This study confirmed that significant correlations exist between quadriceps muscle activity and stability limits and gait velocity in stroke patients.

Quadriceps muscle activity controls vertical moving velocity of the center of mass and buffers the impact from load on the joints by adjusting the amount of knee flexion ${ }^{11,12)}$. Quadriceps muscle strengthening should initially be considered to improve functional performance in stroke patients ${ }^{13}, 14$.

Table 1. General subject characteristics and dependent variables $(\mathrm{N}=55)$

\begin{tabular}{lc}
\hline Variable & Mean \pm SD (\%) \\
\hline Gender & $30 / 25$ \\
Male/Female (\%) & $(54.5 / 45.6)$ \\
Etiology & $35 / 20$ \\
Infarction/Hemorrhage (\%) & $(63.6 / 36.4)$ \\
Age (years) & $58.7 \pm 3.8$ \\
Height (cm) & $165.5 \pm 8.9$ \\
Mass (kg) & $65.1 \pm 5.9$ \\
Post-stroke duration (month) & $4.8 \pm 1.1$ \\
MMSE-K (score) & $26.4 \pm 2.8$ \\
VL \%RVC (\%) & $31.9 \pm 4.6$ \\
VM \%RVC (\%) & $27.2 \pm 5.2$ \\
LOS (cm ${ }^{2}$ ) & $90.5 \pm 9.1$ \\
GV (m/s) & $0.4 \pm 0.1$ \\
\hline MMSE-K: Korean version of the mini-mental state examina- \\
tion; VL \%RVC: vastus lateralis \% reference voluntary con- \\
traction; VM \%RVC: vastus medialis \% reference voluntary \\
contraction; LOS: limits of stability; GV: gait velocity
\end{tabular}

Table 2. Correlation between quadriceps muscle activation and LOS and gait velocity $(\mathrm{N}=55)$

\begin{tabular}{lccc}
\hline & $\begin{array}{c}\text { VM \%RVC } \\
(\%)\end{array}$ & $\begin{array}{c}\text { LOS } \\
\left(\mathrm{cm}^{2}\right)\end{array}$ & $\begin{array}{c}\mathrm{GV} \\
(\mathrm{m} / \mathrm{s})\end{array}$ \\
\hline VL \%RVC (\%) & 0.32 & $0.75^{* *}$ & $0.74 * *$ \\
VM \%RVC (\%) & & $0.85^{* *}$ & $0.86^{* *}$ \\
LOS $\left(\mathrm{cm}^{2}\right)$ & & & $0.85^{* *}$ \\
\hline
\end{tabular}

VL \%RVC: vastus lateralis \% reference voluntary contraction; VM \%RVC: vastus medialis \% reference voluntary contraction; LOS: limits of stability; GV: gait velocity. $* * \mathrm{p}<0.01$ 
In the knee joint, $80 \%$ of total extension torque is produced by the vastus medialis and vastus lateralis of the quadriceps, and the muscle activity ratio for each of these in a normal individual is about $1: 1^{15)}$. Compared to a normal person, a patient with knee joint malfunction presents a difference in the muscle activity ratio ${ }^{16)}$. This study did not find significant correlations between the vastus medialis and vastus lateralis muscle activity. This may be due to the effect of muscle imbalance caused by differences in the muscle activity ratio in stroke patients who also have malfunctioning knee joints, according to pilot studies.

When et al. ${ }^{17)}$ compared and measured muscle activity in 15 stroke patients and 10 normal subjects of similar ages during balance maintenance in various environments, and the muscle activity of the vastus medialis and vastus lateralis showed a significant difference. Furthermore, this study revealed a significant correlation between muscle activity of the vastus medialis and vastus lateralis and balance. Quadriceps activity is thought to show a correlation with balance ability after a decrease in asymmetrical weight-bearing. This study also confirmed a significantly higher correlation between the vastus medialis and balance, which is considered necessary for selective muscle strengthening of the vastus medialis to improve balance.

Boudarham et al. ${ }^{18)}$ analyzed the length of a single step and gait velocity causing fatigue in the quadriceps, hamstring, and gastrocnemius in 13 stroke patients. The result showed that fatigue of the quadriceps significantly decreased walking ability, while improvement of quadriceps activity showed a high correlation with gait velocity, stride, and weight-bearing ratio ${ }^{19,20)}$. This study also revealed significant correlations between gait velocity and muscle activity of the vastus medialis and vastus lateralis. Quadriceps muscle activity was found to show a correlation with gait velocity due to improvement in the stance phase of the gait cycle by providing stability to the knee joints.

This study confirmed that a significant correlation exists between quadriceps muscle activity and balance and gait. However, the study has limitations. It is difficult to generalize the results for all stroke patients because of the small number of subjects and regional limits. A study of the effect of quadriceps strength training on balance and quality of life in stroke patients is therefore necessary.

\section{ACKNOWLEDGEMENT}

The research was has been conducted by the research grant of Sehan university in 2016.

\section{REFERENCES}

1) Shim SH, Yu JH, Jung JH, et al.: Effects of dual-task performance on postural sway of stroke patients with experience of fall. J Phys Ther Sci, 2012, 24: 975-978. [CrossRef]

2) Snow LM, Low WC, Thompson LV: Skeletal muscle plasticity after hemorrhagic stroke in rats: influence of spontaneous physical activity. Am J Phys Med Rehabil, 2012, 91: 965-976. [Medline] [CrossRef]

3) Chow JW, Stokic DS: Variability, frequency composition, and complexity of submaximal isometric knee extension force from subacute to chronic stroke. Neuroscience, 2014, 273: 189-198. [Medline] [CrossRef]

4) Gerrits KH, Beltman MJ, Koppe PA, et al.: Isometric muscle function of knee extensors and the relation with functional performance in patients with stroke. Arch Phys Med Rehabil, 2009, 90: 480-487. [Medline] [CrossRef]

5) Hashidate H, Shiomi T, Sasamoto N: Effects of 6 months combined functional training on muscle strength, postural balance and gait performance in community-dwelling individuals with chronic stroke hemiplegia. J Phys Ther Sci, 2011, 23: 617-623. [CrossRef]

6) Higuchi T, Cinelli ME, Greig MA, et al.: Locomotion through apertures when wider space for locomotion is necessary: adaptation to artificially altered bodily states. Exp Brain Res, 2006, 175: 50-59. [Medline] [CrossRef]

7) Lee KB, Kim JH, Lee KS: The relationship between motor recovery and gait velocity during dual tasks in patients with chronic stroke. J Phys Ther Sci, 2015, 27: 1173-1176. [Medline] [CrossRef]

8) Kim JH: The effects of whole body vibration exercise on balance and lower extremity muscle activity in stroke patients. J Kor Phys Ther, 2013 , 25: 266-272.

9) Baek IH, Kim BJ: The effects of horse riding simulation training on stroke patients' balance ability and abdominal muscle thickness changes. J Phys Ther Sci, 2014, 26: 1293-1296. [Medline] [CrossRef]

10) Kutilek P, Socha V, Viteckova S, et al.: Quantification of gait asymmetry in patients with ankle foot orthoses based on hip-hip cyclograms. Biocybermetics Biomed Eng, 2014, 34: 46-52. [CrossRef]

11) Pietrosimone B, Lepley AS, Murray AM, et al.: Changes in voluntary quadriceps activation predict changes in muscle strength and gait biomechanics following knee joint effusion. Clin Biomech (Bristol, Avon), 2014, 29: 923-929. [Medline] [CrossRef]

12) Liu H, Wu W, Yao W, et al.: Effects of knee extension constraint training on knee flexion angle and peak impact ground-reaction force. Am J Sports Med, 2014, 42: 979-986. [Medline] [CrossRef]

13) Den Otter AR, Geurts AC, Mulder T, et al.: Abnormalities in the temporal patterning of lower extremity muscle activity in hemiparetic gait. Gait Posture, 2007, 25: 342-352. [Medline] [CrossRef]

14) Severinsen K, Jakobsen JK, Overgaard K, et al.: Normalized muscle strength, aerobic capacity, and walking performance in chronic stroke: a population-based study on the potential for endurance and resistance training. Arch Phys Med Rehabil, 2011, 92: 1663-1668. [Medline] [CrossRef]

15) Ng GY, Zhang AQ, Li CK: Biofeedback exercise improved the EMG activity ratio of the medial and lateral vasti muscles in subjects with patellofemoral pain syndrome. J Electromyogr Kinesiol, 2008, 18: 128-133. [Medline] [CrossRef]

16) Makhsous M, Lin F, Koh JL, et al.: In vivo and noninvasive load sharing among the vasti in patellar malalignment. Med Sci Sports Exerc, $2004,36: 1768-1775$. 
[Medline] [CrossRef]

17) Wen H, Dou Z, Cheng S, et al.: Activity of thigh muscles during static and dynamic stances in stroke patients: a pilot case-control study. Top Stroke Rehabil, 2014, 21: 163-172. [Medline] [CrossRef]

18) Boudarham J, Roche N, Pradon D, et al.: Effects of quadriceps muscle fatigue on stiff-knee gait in patients with hemiparesis. PLoS ONE, 2014 , 9: e94138. [Medline] [CrossRef]

19) Patten C, Lexell J, Brown HE: Weakness and strength training in persons with poststroke hemiplegia: rationale, method, and efficacy. J Rehabil Res Dev, 2004, 41: 293-312. [Medline] [CrossRef]

20) Haacke C, Althaus A, Spottke A, et al.: Long-term outcome after stroke: evaluating health-related quality of life using utility measurements. Stroke, 2006, 37: 193-198. [Medline] [CrossRef] 